\title{
Predicting the Vegetation Expansion in Selangor, Malaysia using the NDVI and Cellular Automata Markov Chain
}

\author{
Goma Bedawi Ahmed ${ }^{1,2}$, Abdul Rashid M. Shariff ${ }^{1}$ \\ ${ }^{1,2}$ Geospatial Information Science Research Centre (GISRC), of Advanced Technology, Faculty of \\ Engineering, University Putra Malaysia, 43400 UPM, Serdang, Selangor Darul-Ehsan, Malaysia \\ ${ }^{2} \mathrm{Arab}$ Center for Desert Research and Development of Desert Communities Morzok- Libya \\ Joma762001@gmail.com; rashidsnml@gmail.com
}

\begin{abstract}
This study analyzed Landsat data to investigate the expansion of vegetation in the state of Selangor, Peninsular Malaysia, using the NDVI and Cellular Automate Markov Chain method. Two sets of Landsat data acquired in 2000 and 2015 were analyzed. The Vegetated areas in each Landsat scene were extracted from NDVI images. Then, the two image sets, 2000 and 2015 , were input into Idrisi software where the Markov algorithm was used to predict the vegetation expansion for the year 2030. The results show that the vegetated areas increased by $45 \%$ between 2000 and 2015. Similarly, a 55\% increase in vegetation for the next 15 years (2015 to 2030 ) was predicted. This study suggests the need for better planning and management to balance between vegetation and urban area expansion in Selangor.
\end{abstract}

Keywords: Vegetation expansion, Markov chain, Selangor

\section{Introduction}

Land cover change detection and vegetation expansion analysis are significant techniques which are widely used for planning and managing land [1]. In recent years, remote sensing and geographic information systems have been employed for several applications including the detection of land cover changes [2]. Landsat imagery is a common satellite image utilized in studies on land use and cover because of its easy availability. Landsat TM spectral channels are used to map vegetation and soil types, as well as other main landscape patterns, such as barren lands and grasslands [3, 4].

The normalized difference vegetation index (NDVI) is one of the most important indicators of vegetation cover in specific areas from remotely sensed data acquired using the space borne sensors [5]. The NDVI has been used significantly to detect land cover changes caused by human activities, such as construction and other developmental projects. Also, it has been widely used to analyses the spatio-temporal changes of vegetation coverage [6]. The vegetation index measures the balance between the energy received and those emitted by earth objects using the Red and NIR bands [7].

Production helps decision making to form the best management planning and for better source sustainability. To achieve this, the NDVI had to be applied because this study has focused on the expansion of and changes in the vegetated area. The Marcove algorithm was applied to predict the future situation for the next 15 years. This paper primarily aims to determine the land cover changes in the state of Selangor by using the NDVI index and predicting the changes throughout the next 15 years in the study area.

\section{Material and Method}

\subsection{Study Area}

Selangor is one of the 11 states in Peninsular Malaysia (Fig. 1). The location of Selangor is within latitude 3.519863N and longitude 101.538116E and has nine districts. It is bounded on the north by Perak, Pahang on the East, Negeri Sembilan on the south, and by the Strait of Melaka on the west. Selangor is the most populous state in Malaysia with 5,411,324 inhabitants and has experienced rapid development due to modernization [8]. Economically, the state took the lead with a GDP of RM 128.815 billion (roughly USD 42 billion) in 2014, making up 23\% of the whole Malaysian GDP. The state has a high standard of living and the lowest poverty rate of all the states [6,9]. 


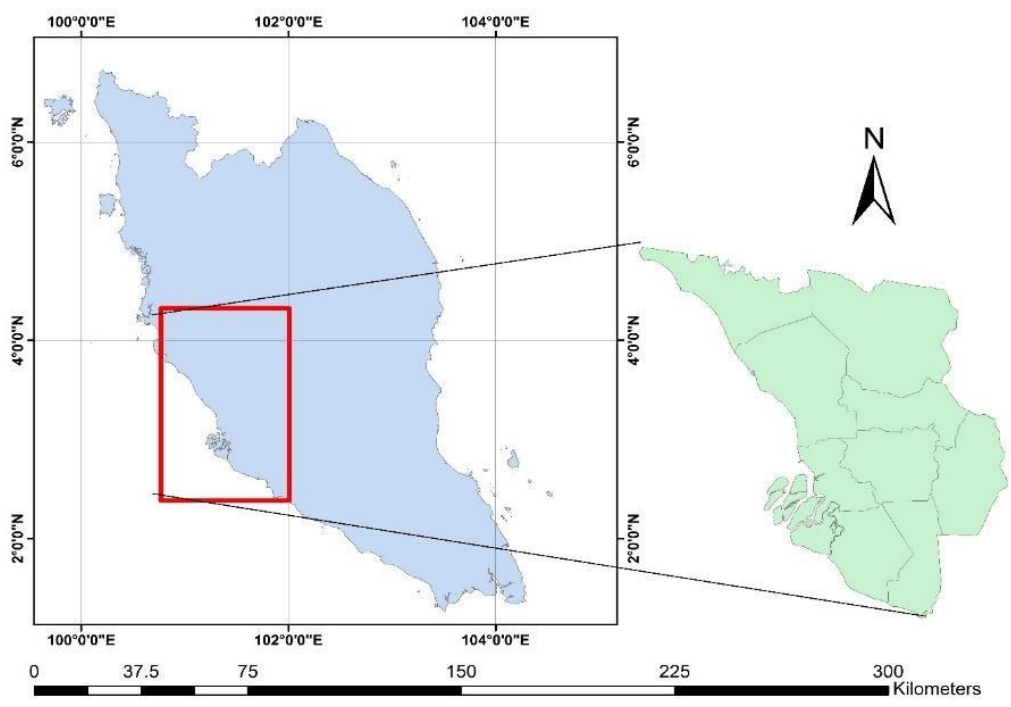

Fig. 1: Study area.

\subsection{Data Used}

This study utilized Landsat satellite images of 2000 and 2015 downloaded free of charge from the United States Geological Survey (USGS) Earth Explorer website (http://earthexplorer.usgs.gov/). Table1 provides the detailed properties of each dataset.

Table 1: Properties of Landsat images used.

\begin{tabular}{|l|l|l|l|}
\hline Image & Acquisition date & Spatial & spectral \\
\hline TM & Jun 2000 & $30 \mathrm{M}$ & 8 BANDS \\
\hline Landsat 8 & Jun 2015 & $30 \mathrm{M}$ & 11 BANDS \\
\hline
\end{tabular}

\subsection{Methodology}

The data was first preprocessed to correct the systematic and non-systematic errors resulting from the sensor and atmospheric sources. The two images were geometrically calibrated using the image-to-image registration. Then, the digital numbers were calibrated and converted into radiance using the ENVI 4.80.0. Then, the radiance values were converted into reflectance. In addition, the reflectance was atmospherically corrected using dark object subtraction to reduce the effects of the atmospheric layer and make the matching between the two images accurate [7]. The corrected images were subset based on the shapefile of the state boundary, and only the red and near infrared bands were left, which were used to compute the NDVI for the respective year. The NDVI maps were further reclassified to separate the vegetation from non-vegetation areas based on a threshold determined through trial and error and comparison with the Google Earth map. The two NDVI layers were used to analyze the vegetation expansion between the two image acquisition years and to predict the expansion of the vegetated areas in the study area for the next 15 years. This was performed in the Cellular automate Markov chain [8] and the algorithm in the Idrisi package.

The MARKOV analyzed a pair of land cover images and output a transition probability matrix, a transition area matrix, and a set of conditional probability images, each containing useful information about the changes [9]. The transition probability matrix recorded the probability of each land cover category. On the other hand, the transition area matrix recorded the number of pixels that were expected to change from each land cover type to each other land cover type over the specified length of time. In both cases, the rows represent the old land cover categories and the columns represent the new categories. Lastly, the conditional probability images reported the probability that each land cover type would be found at each pixel over the time units. The output conditional probability images were used as direct input for the specification of the prior probabilities in the Maximum Likelihood Classification of the remotely sensed imagery (such as with the MAXLIKE and BAYCLASS modules) [9-11]. A raster group file was also created listing all the conditional probability images. 


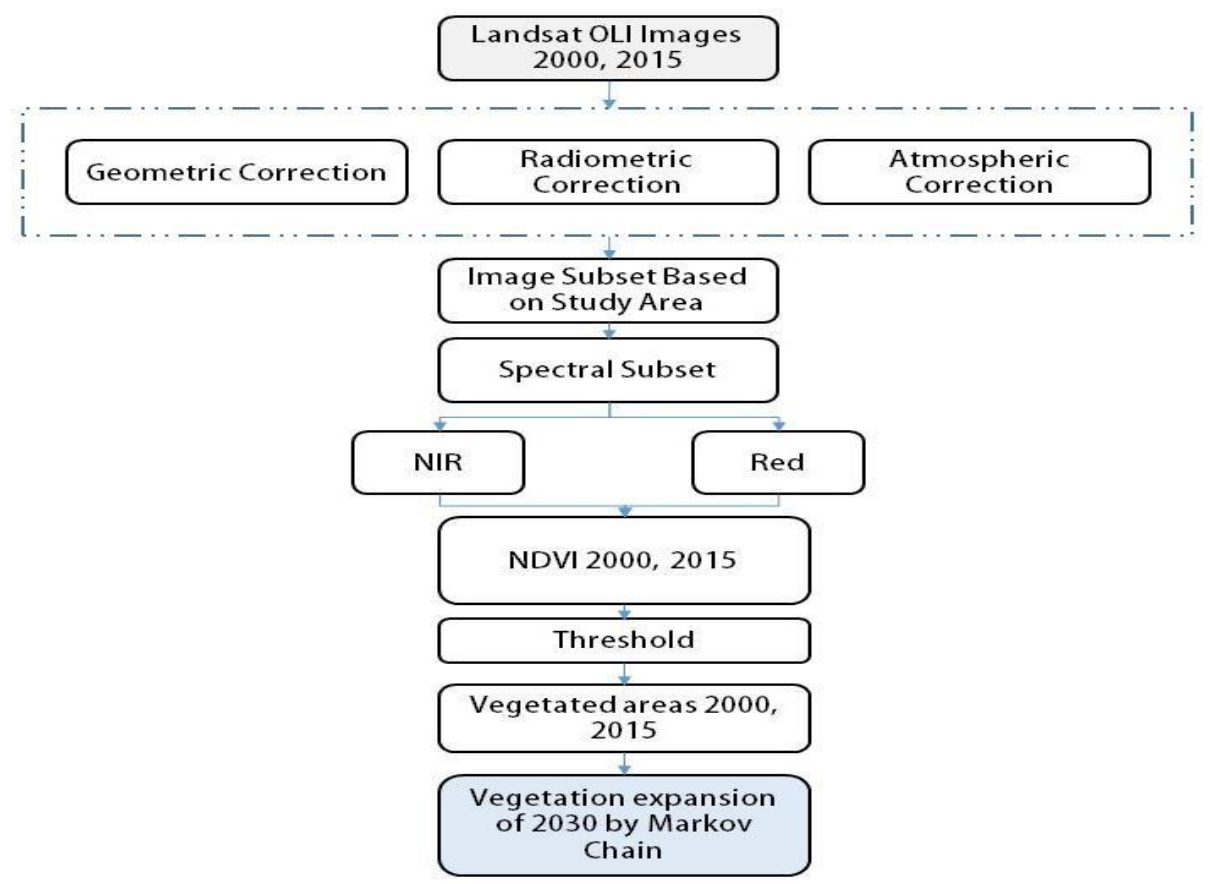

Fig. 2: Data processing and analysis workflow.

\section{Results}

The land cover analysis using the NDVI index has been a valuable metric to distinguish between vegetated and nonvegetated cover types. Negative values of the NDVI index refers to a lack of vegetation, which are those that belong to other land use/cover types, such as built up areas. Similarly, a zero value indicates water bodies whereas positive values indicate different levels of vegetation. Meanwhile, increases in the positive values indicate the health of the vegetation in question $[12,13]$. Fig. 2 presents the classified map of the years 2000 and 2015 into two classes, vegetated and non-vegetated areas.

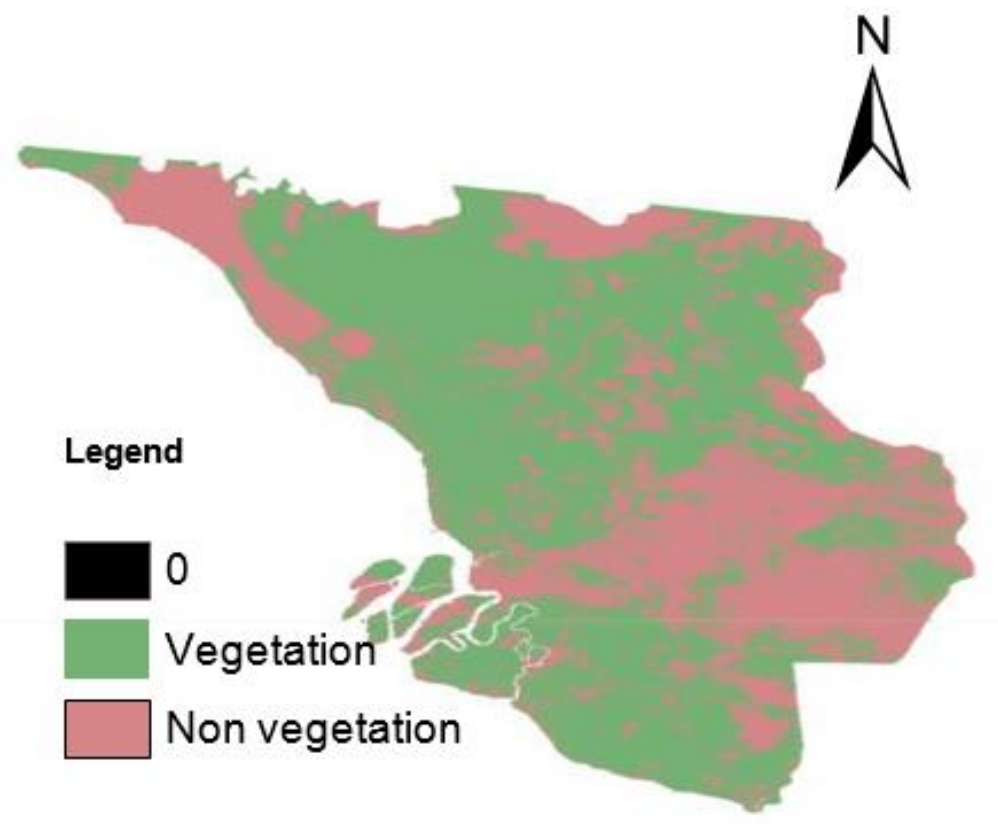

Fig. 3: vegetation expansion map for year 2010.

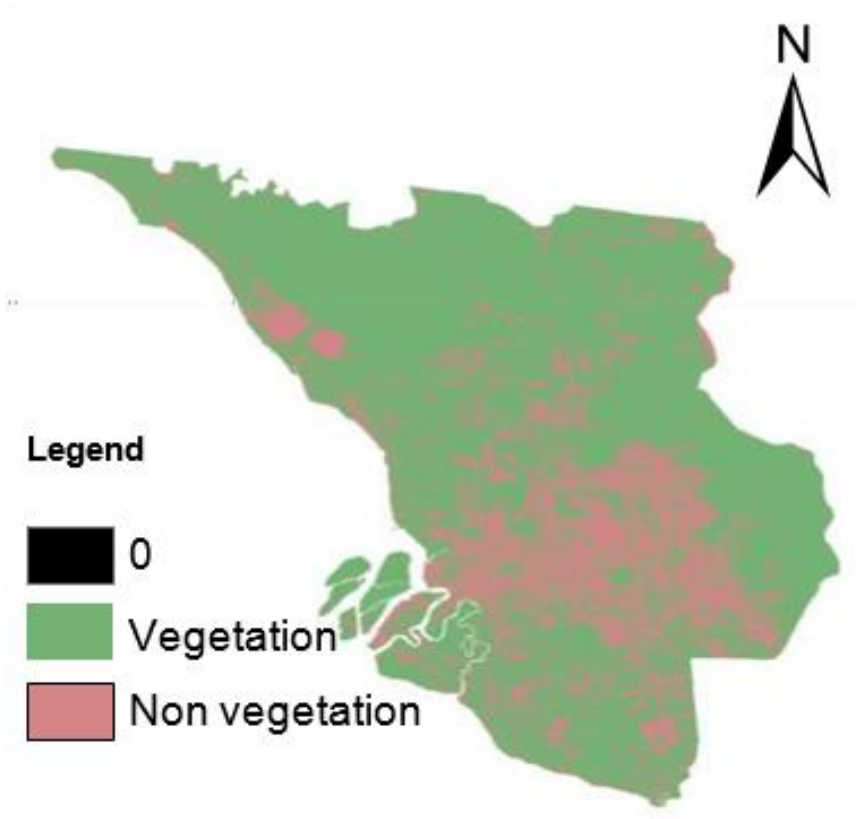

Fig. 4: vegetation expansion map for year 2000 . 
Table 2: Aside from the statistical values and the algorithm also produced a prediction.

\begin{tabular}{|l|l|l|l|l|l|l|l|}
\hline $\begin{array}{l}\text { NDVI } \\
\text { classes }\end{array}$ & $\begin{array}{l}\text { NDVI } \\
\text { class areas } \\
2000\end{array}$ & $\begin{array}{l}\text { NDVI } \\
\text { class }\end{array}$ & $\begin{array}{l}\text { areas } \\
2015\end{array}$ & $\begin{array}{l}\text { Changes between } \\
2000 \text { and 2015 }\end{array}$ & Prediction 2030 & \\
\hline ha & $\%$ & ha & $\%$ & ha & ha & $\%$ \\
\hline $\begin{array}{l}\text { non } \\
\text { vegetated }\end{array}$ & 2180814 & $25 \%$ & 5314285 & $60 \%$ & 3133471 & 4819241 & $55 \%$ \\
\hline vegetated & 6666075 & $75 \%$ & 3532604 & $40 \%$ & -3133471 & 4027648 & $45 \%$ \\
\hline Total & 8846889 & 100 & 8846889 & 100 & 8846889 & 8846889 & 100 \\
\hline
\end{tabular}
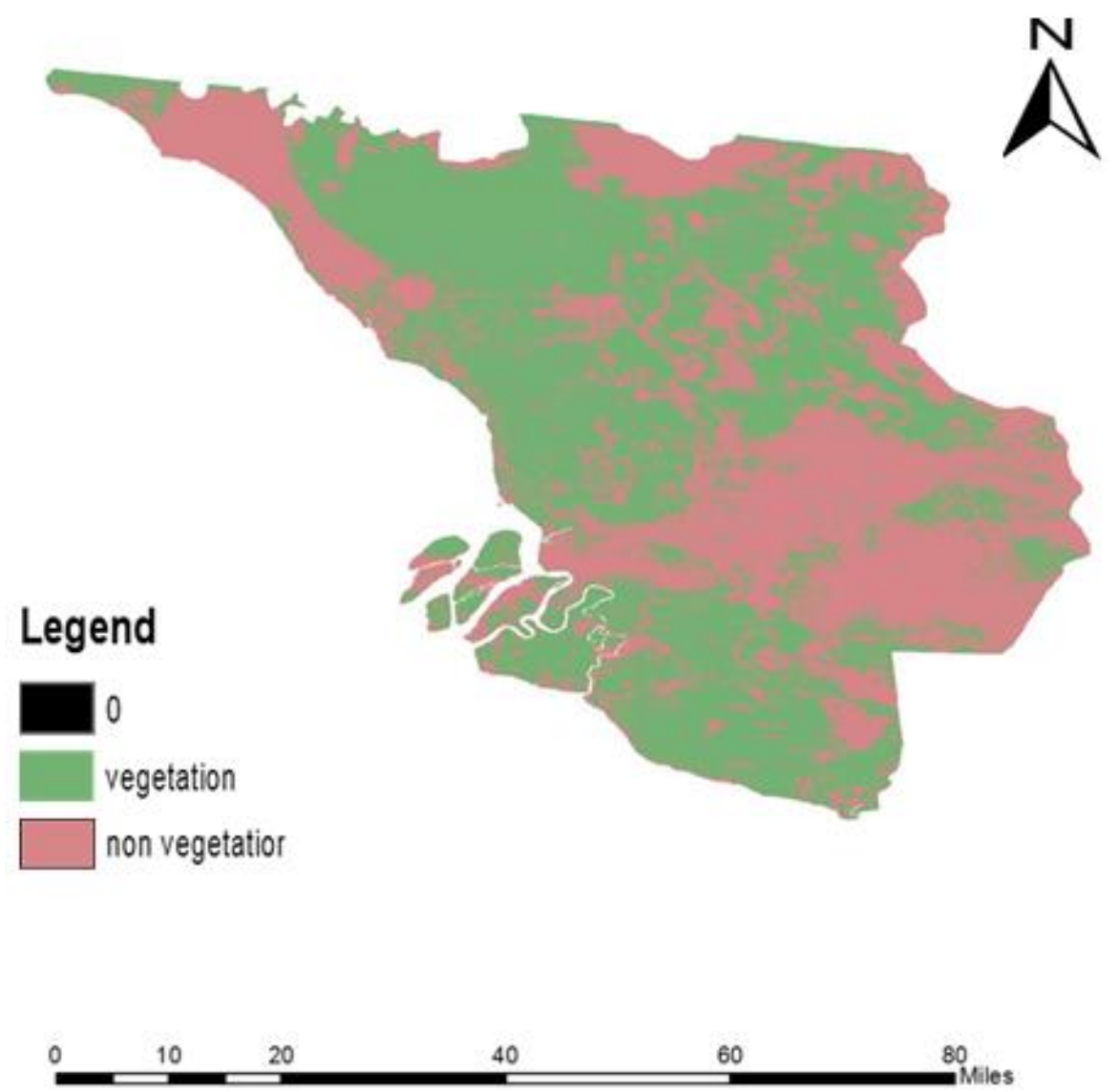

Fig. 5: Predicted vegetation expansion for the year 2030.

\section{Discussions}

Changes in the vegetation cover are shown in Table 2 and Fig. 3. The analysis indicates a decrease in the vegetated area from 6666075ha to 2180814 in 2000 and 2015, respectively. The decrease shows the extent to which urban development had taken place within the time frame, claiming about 3133471 ha that amounted to a loss of 25 percent to urban sprouting. According to the report of the Malaysia Departments of Agriculture and Statistics, the rapid development in the state, especially the capital city, is attributed to the industrialization and rural-urban migration for job opportunities and a better standard of living. Conversely, there was an increase in non-vegetated area from 2180814ha to 5314285ha between 2000 and 2015 resulting in a 60 percent gain (Table 2). Areas known to have a high density of forest, such as Gombak, Hulu 
Langat, and Hulu Selangor, are now dominated by sparse vegetation. So, also are some parts of Kuala Selangor. In a similar development, a negative change in land cover from vegetated to urban area between 2000 and 2015 has more prominence in Sepang, Kuala Langat, and Sabak Bernam districts. These areas are a little far from the city center where the cost of land is affordable for the average income earners.

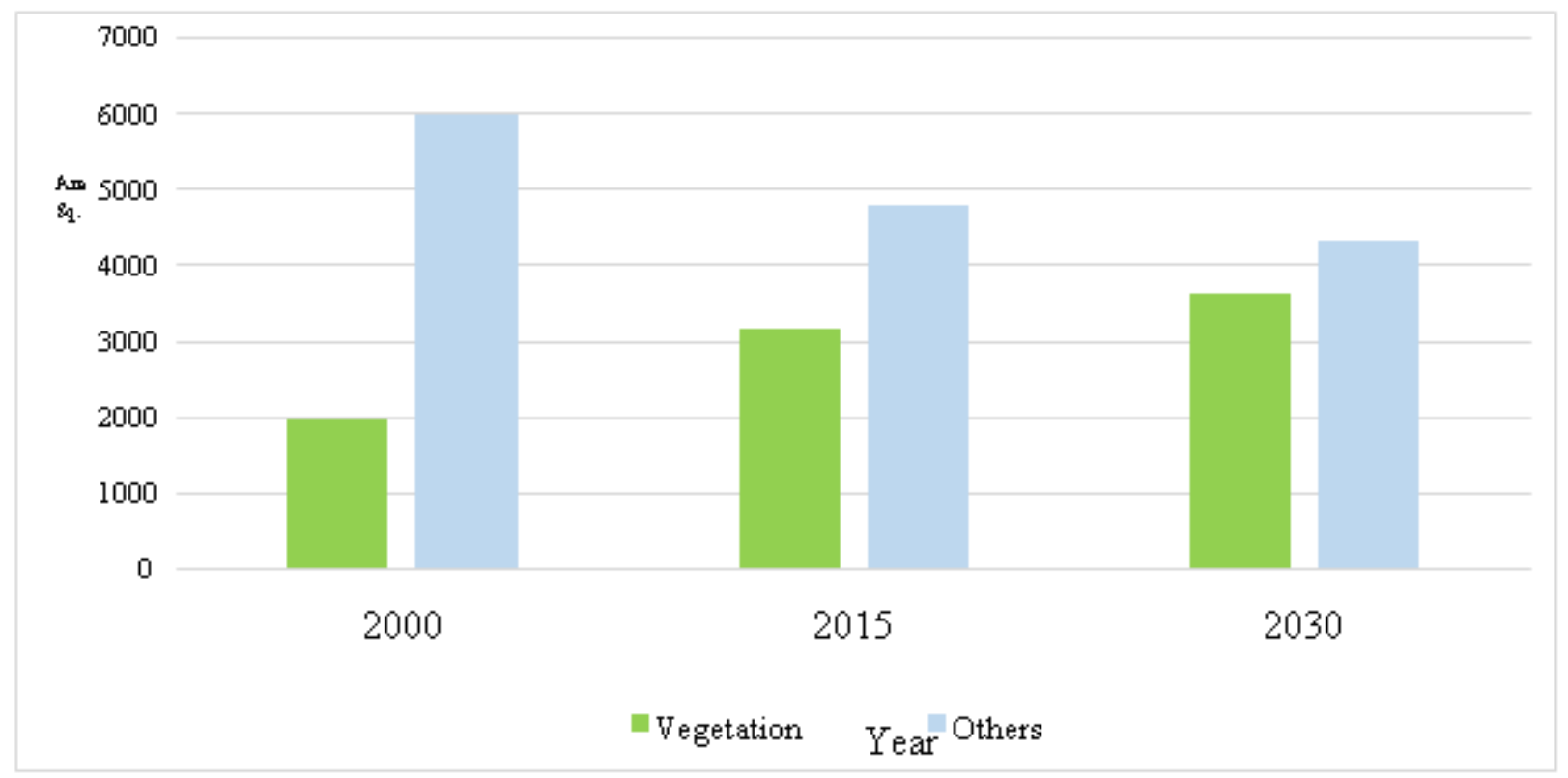

Fig. 6: Shows the change classes in deferent year in the study area.

In view of the changes observed between 2000 and 2015, the vegetation pattern was predicted for the next 15 years. The prediction shows that by 2030 there will be 4819241 ha in the non-vegetated area and 4027648 ha in the vegetated area.

\section{Conclusion}

The NDVI index is an important indicator used to identify changes in land use and cover because of urban and economic development. Effective factors on land cover can be determined through extracted values of the NDVI map. Nowadays, the NDVI index has become a commonly used method in urban studies for the evaluation of land cover changes and urban growth patterns. The results of the study confirmed that the dense vegetation areas in the study area declined as a result of several causes, such as urban and economic development because of population growth and deforestation, which can be changed if multiple types of commercial agricultural crops, such as oil palm, are planted. The negative changes in the vegetation cover in Selangor that occurred between 2000 and 2015, at 45\%, were due to land use activities based on the department of town planning of Selangor but it is expected to increase to 55\% by the year 2030. The results of the NDVI index can be used as indicators for future trends on land cover changes and for identifying effective factors on vegetation cover for the better understanding of planners and decision makers on the issue.

\section{References}

[1] J. Yu, Y. Chen, and J. Wu, "Cellular automata and GIS based land use suitability simulation for irrigated agriculture," in 18th world IMACS/MODSIM Congress, 2009, pp. 13-17.

[2] D. Mitsova, W. Shuster, and X. Wang, "A cellular automata model of land cover change to integrate urban growth with open space conservation," Landscape and Urban Planning, vol. 99, pp. 141-153, 2011.

[3] J. Yu, Y. Chen, J. Wu, and S. Khan, "Cellular automata-based spatial multi-criteria land suitability simulation for irrigated agriculture," International journal of geographical information science, vol. 25, pp. 131-148, 2011.

[4] G. Gao and C. Chang, "Changes In CEC And Particle Size Distribution Of Soils Associated With Long-Term Annual Applications Of Cattle Feedlot Manure," Soil Science, vol. 161, pp. 115-120, 1996. 
[5] A. Ceballos-Silva and J. Lopez-Blanco, "Delineation of suitable areas for crops using a Multi-Criteria Evaluation approach and land use/cover mapping: a case study in Central Mexico," Agricultural Systems, vol. 77, pp. 117-136, 2003.

[6] M. M. S. MALAYSIA, "Department of Statistics, Malaysia," 2014.

[7] P. Backlund, A. Janetos, and D. Schimel, "The effects of climate change on agriculture, land resources, water resources, and biodiversity," Synthesis and assessment product, vol. 4, 2008.

[8] K. B. Basir and M. R. Board, "Future direction of the Malaysian rubber industry," in Rubber Planters' Conference 2007, PWTC, Kuala Lumpur, Malaysia, 5-6 Jul 2007, 2007.

[9] F. Zabel, B. Putzenlechner, and W. Mauser, "Global Agricultural Land Resources-A High Resolution Suitability Evaluation and Its Perspectives until 2100 under Climate Change Conditions," PloS one, vol. 9, p. e107522, 2014.

[10] K. Biro, B. Pradhan, M. Buchroithner, and F. Makeschin, "Land use/land cover change analysis and its impact on soil properties in the northern part of Gadarif region, Sudan," Land Degradation \& Development, vol. 24, pp. 90-102, 2013.

[11] A. M. Nedal, S. M. SA, and J. M. Akhir, "Landuse evaluation for Kuala Selangor using remote sensing and Gis technologies," Geografia, vol. 4, pp. 21-42, 2007.

[12] A. Lufafa, M. Tenywa, M. Isabirye, M. Majaliwa, and P. Woomer, "Prediction of soil erosion in a Lake Victoria basin catchment using a GIS-based Universal Soil Loss model," Agricultural systems, vol. 76, pp. 883-894, 2003.

[13] J. Ratnasingam, G. Ramasamy, F. Ioras, J. Kaner, and L. Wenming, "Production potential of rubberwood in Malaysia: Its economic challenges," Notulae Botanicae Horti Agrobotanici Cluj-Napoca, vol. 40, pp. 317-322, 2012. 